Mr. Millington, my assistant, that he had been engaged in a drunken quarrel. He complained of much pain in the head, and said he had been ill-treated two days before by some men a few miles from the town. In the evening he was feverish and restless. On the following morning he was better, ancl appeared relieved by the copious action of a cathartic which was given him. He came down stairs and smoked a pipe and drank some porter in company with the frequenters of the inn where he was lodging. He was again restless at night and was found insensible in the morning, with convulsive twitchings of the muscles of the face, the limbs were entirely undisturbed. He was bled largely, in connection with the employment of other means, but he speedily sunk into a state of coma, and died early on the following morning.

Sectio-capitis, August 13.-Considerable extravasation around the right orbit. No other contusion or wound discovered. The superior surface of the brain exhibited a highly congested appearance. The inferior surface of the right anterior lobe bore marks of a recent laceration, about an inch in length; the substance of the organ around was dark and pulpy. There was an exudation of blood in this situation, diffused in a semi-coagulated state beneath the anterior and middle lobe over the orbitar plate of the frontal bone, and the sphenoid and temporal bones of that side. A fracture was observed transversely across the petrous portion of the temporal bone, extending through the occipital to the length of about four inches in the whole. In the immediate vicinity of the fracture, between the dura mater and the occipital bone of the same side, a copious extravasation of blood had taken place from rupture of the lateral sinus, the course of which was crossed by the fracture. About an ounce of strawcoloured fluid was found at the base of the brain, and a similar quantity in each of the lateral ventricles. The floors of the ventricles, and the thalami optici appeared to be preternaturally softened. A deposit of lymph was observed on the pons varolii, and on the medulla oblongata.

This case became the subject of judicial inquiry. It appeared probable, that the deceased being intoxicated, attacked with a sickle a fellow labourer who, in selfdefence, struck him a violent blow on the head with his fist and knocked him down. He was found three hours after lying insensible in the place where he fell. He was left there, but soon after got up and walked of his own accord to Waldon, a distance of between two or three miles. $\mathrm{He}$ was incapable of giving any distinct account of himself, or of the injury he had received. He came to the Castle Inn on the 7 th, complained of headache, but made no application for medical assista nce until the 9 th, as above detailed, and then only at the urgent desire of the landlady. The fracture of the skull, laceration of the brain, and rupture of the lateral sinus. occurred doubtless at one and the same time, as the result of the blow, or the consequent fall. In spite of these lesions he was able to walk some distance, to smoke and to drink, and for the first three or four days after the reception of the injuries there were no symp- toms to lead to a suspicion of the mischief which was revealed by the examination post-mortem.

In this case the effusion of blood from the lacerated vessels was in all probability slight in the first instance, but gradually increased until the amount of pressure became sufficient to destroy the functions of the brain.

December 1, 1849.

\section{CASE OF MALFORMATION,}

(Read at the Anniversary Meeting of the Association, held at Worcester, August 1st and ind, 1849.)

By JOHN JONES, Esq., M.R.C.S., Derby.

April, 1848.-Mrs. B. was delivered at the full period of pregnancy, of a remarkably large and apparently fine child. On examination, however, the following malformation was discovered. The space between the epigastrium and umbilicus is unusually long, and that between the umbilicus and pubes correspondingly short. Below the umbilicus there is a deficiency of the abdominal muscles and integuments, extending to the pubes, and leaving an opening, which at first seemed to be occupied by granulations, but was found principally to be filled up by an oval-shaped body, soft and receding on pressure, and when pressed upon a fluid escaped, proving it to be the urinary bladder, the exposed surface of which was exterior to the peritoneal reflexion, was vascular, and could with difficulty be distinguished from the surrounding granulations. Below the pubes is a portion of a penis, consisting only of the inferior half of that organ, as if divided by a longitudinal section, leaving exposed the floor of the urethra situated between the two halves of the corpora cavernosa, which terminate in two tubercular-shaped discs formed by the inferior half of the glans penis. The orifice of the urethra is a small opening situated under the symphisis pubis, and can only be discovered by pressing on the bladder, when urine is observed to escape from it. Lacunæ are also visible on the exposed surface of the urethra. The scrotum containing the testis appears to be natural; but the anus is situated unusually near to the scrotum.

The following is the present appearance of the malformation:-The preternatural opening is much contracted; the bladder is less vascular, occupies a much smaller space than at first, and seems more intimately united with the surrounding parts. The urine, of course, continues to ooze from the urethral orifice, but seems to cause little or no irritation, and with care, the little fellow is kept tolerably comfortable. I think some mechanical contrivance might be devised which would obviate in some measure the inconvenience arising from the involuntary flow of urine.

The following circumstances occurred during pregnancy, which, in the mother's estimation, sufficiently account for the malformation:-About the fourth month of gestation she was greatly alarmed in consequence of a hay-stack belonging to her husband having been burnt. At the same time her daughter, about seven years old, was affected with chronic glandu- 
lar disease, which terminated fatally, and for which a perpetual blister was directed to be applied to the neck. The mother dressed the blister herself daily, but always felt great horror at the appearance of the sore.

A satisfactory explanation of the strange freaks of nature which occasionally occur, both in the animal and vegetable kingdoms, has never yet been given, and I suspect that the mystery in which the subject of monstrosity is involved must be considered as amongst the arcana of nature with which we are not permitted fully to be acquainted. That the human fotus can be marked through the medium of the mother's imagination has been the popular belief for ages, and although denied by philosophical incredulity, yet the instances both recorded and of daily occurrence are so numerous in which the child has been marked apparently in consequence of strong mental impressions of the mother occurring during pregnancy, that the question is by no means settled, whether they may not be considered, at least occasionally, in the relation of cause and effect.

Bodily injuries received by the mother are followed sometimes by the appearance of similar injuries produced on the foetus. Some years ago a case occurred in my practice, in which the mother during the latter months of pregnancy fell, and hurt her knee, from which the skin was abraded to a considerable extent. When the child was born, an injury exactly similar was observed on one of its knees. Although we might not be justified in believing this occurrence to have been the result of cause and effect, it must at least be considered as a very interesting and remarkable coincidence.

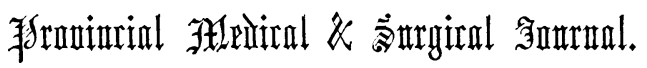

WEDNESDAY, JANUARY 9, 1850.

IN the recent trial QueLch $v$. WAKLEY, we have portrayed one of the many painful phases of medical life-the manifestation of ingratitude where the benefits received merit the utmost thankfulness. There is something, however, in the present instance, more than commonly revolting. Among the purse-proud, the selfish, and the ignorant of the upper classes, a knowledge of human nature would a priori lead us to expect to have our motives and actions misconstrued, and the good we have conferred unacknowledged or forgotten with the discharge of its conventional pecuniary remuneration; but among those who have nothing but thanks to give in return for the skill and attention which has saved a life, or ministered to the wants and sorrows of a lingering malady, to their honor be it said, ingratitude is rarely met with; having nothing else to give, the poor man is generally prodigal of his thanks. Not so the sordid being who is plaintiff in the present case, of which the following are the brief particulars :-

A child receives a fracture of the thigh, and is placed in the Royal Free Hospital, under the superintendence of Mr. WAKLEY, jun.; there she unfortunately becomes the subject of scarlatina, in consequence of which the reparative process is suspended. Upon this the father, whether at his own suggestion or the instigation of others we know not, sues the surgeon for mala praxis, adducing among other charges that such has been the want of cleanliness and eare-that his poor child had actually become the subject of venereal disease from the use of infected bandages. The result of the trial has been the complete denial of this and other accusations, and the establishment on the testimony of the first surgical authorities, of the correctness of the defendant's treatment.

We congratulate Mr. WAKLEY on the failure of the attempt to slander his professional reputation, but we trust that the transaction will stimulate him and the other medical officers to look more closely into the internal management of the Institution to which they are attached. That this has not always been what it ought to be, we should presume from the fact, that at no very distant period an influential contemporary made this very hospital the subject of repeated animadversion. We are in the possession of information which leads us to suppose that there are still some grounds for complaint, as there is room for improvement.

But dismissing the case in reference to its immediate bearings, we would be allowed to indulge in some reflections on the relative positions of the hospital medical officer and his patient. Next to the sacerdotal office, there is to our mind no position attended with responsibilities so sacred as that of the hospital Physician or Surgeon; and it is an egregious anomaly in the constitution of our charities, that duties so urgent should be required to be discharged without fee or reward. This, however, is not the question we have now to consider. The office, with all its labours and anxieties is eagerly sought after, and to the conscientious mind the obligation is as binding as if these were cancelled by pecuniary remuneration.

If indeed we were to judge by the florid promises of candidates for these responsible offices, it would be readily concluded that the public 